\title{
A Synthetic Peptide Inhibitor for $\alpha$-Chemokines Inhibits the Growth of Melanoma Cell Lines
}

Shinichiro Hayashi, ${ }^{\star}$ Anna Kurdowska, ${ }^{\star}$ Allen B. Cohen, ${ }^{\star \ddagger}$ Michael D. Stevens, ${ }^{\star}$ Nobumitsu Fujisawa, ${ }^{\star}$ and Edmund J. Miller Department of $*$ Biochemistry and ${ }^{\ddagger}$ Medicine, University of Texas Health Center at Tyler, Tyler, Texas 75710

\begin{abstract}
Melanoma growth stimulatory activity (MGSA/GRO $\alpha$ ) is a 73 amino acid peptide sharing sequence characteristics with the $\alpha$-chemokine superfamily. MGSA/GRO $\alpha$ is produced by diverse melanoma cell lines and reported to act as an autocrine growth factor for the cells. We tested the binding of MGSA/GRO $\alpha$ to melanoma cell lines, Hs 294T and RPMI7951, and found that these cells could bind to MGSA/GRO $\alpha$ but not to interleukin-8.

Recently, we defined a novel hexapeptide, antileukinate, which is a potent inhibitor of binding of $\alpha$-chemokines to their receptors on neutrophils. When antileukinate was added to melanoma cells, it inhibited the binding of MGSA/ GRO $\alpha$. The growth of cells from both melanoma cell lines was suppressed completely in the presence of $100 \mu \mathrm{M}$ peptide. The cell growth inhibition was reversed by the removal of the peptide from the culture media or by the addition of the excess amount of MGSA/GRO $\alpha$. The viability of Hs 294T cells in the presence of $100 \mu \mathrm{M}$ peptide was $>92 \%$. These findings suggest that MGSA/GRO $\alpha$ is an essential autostimulatory growth factor for melanoma cells and antileukinate inhibits their growth by preventing MGSA/GRO $\alpha$ from binding to its receptors. (J. Clin. Invest. 1997. 99:25812587.) Key words: melanoma $\bullet$ neoplastic proteins $\bullet$ growth substances • interleukin-8 $\bullet$ growth inhibitor
\end{abstract}

\section{Introduction}

Melanoma growth stimulatory activity (MGSA) $)^{1 / G R O} \alpha$ is a peptide that was first identified as an autostimulatory growth factor of Hs 294T melanoma cells (1-3). Further studies indicated that it was produced by diverse melanoma cell lines (4) and played an important role in the tumorigenesis and growth of malignant melanoma cells (5). Sequence analysis demonstrated that MGSA/GRO $\alpha$ is a member of the superfamily called " $\alpha$-chemokines" (6). This family of proteins were chemotactic for neutrophils and had substantial sequence ho-

Address correspondence to Edmund J. Miller, Associate Professor of Biochemistry, The University of Texas Health Center, P.O.B. 2003, Tyler, TX 75710. Phone: 903-877-7007; FAX: 903-877-5954; E-mail: ed@uthct.edu

Received for publication 9 December 1994 and accepted in revised form 20 February 1997.

1. Abbreviations used in this paper: MGSA, melanoma growth stimulatory activity; TFA, trifluoroacetic acid.

J. Clin. Invest.

(C) The American Society for Clinical Investigation, Inc.

0021-9738/97/06/2581/07 \$2.00

Volume 99, Number 11, June 1997, 2581-2587 mology, a C-X-C motif near the amino-terminal end, and two additional Cys residues closer to the carboxyl-terminal end. The functions of $\alpha$-chemokines were mediated by receptors on the cell surface membrane (7-9). Recent studies showed the presence of some types of chemokine receptors on melanoma cells. Some melanoma cells possess IL- 8 receptors similar to those on neutrophils (8-11).

Recently, we defined a novel hexapeptide, antileukinate (Ac-RRWWCR- $\mathrm{NH}_{2}$ ), which is a potent inhibitor of binding of $\alpha$-chemokines to the receptors (12). In these studies, we examined the effect of antileukinate on MGSA/GRO $\alpha$ binding to melanoma cell lines and found that it could suppress the growth of melanoma cells.

\section{Methods}

Peptide synthesis. A hexapeptide, RRWWCR with acetylated $\mathrm{NH}_{2}$ terminus and amidated $\mathrm{COOH}$ terminus, antileukinate, was synthesized and purified by Houghten Pharmaceutical Inc. (San Diego, CA) as described previously (12). In some experiments, the antileukinate was radioactively labeled by acetylating the amino terminus with tritiated anhydrous acetic acid. This procedure was carried out at Multiple Peptide Systems (San Diego, CA). The resulting specific radioactivity was $156 \mathrm{Ci} / \mathrm{mol}$.

Cell culture. Melanoma cell lines, Hs 294T and RPMI-7951, were purchased from American Type Culture Collection (Rockville, MD). A liver cancer cell line, Hep G2, was a gift from M.-C. Liu (University of Texas Health Center at Tyler, TX). The cells were maintained in RPMI-1640 medium containing 10\% fetal bovine serum (HyClone Laboratories Inc., Logan, UT), 2 mM L-glutamine, $50 \mathrm{U} / \mathrm{ml}$ of penicillin and $50 \mathrm{mg} / \mathrm{ml}$ of streptomycin.

Binding assays. Recombinant human MGSA/GRO $\alpha$ and IL-8 were purchased from Pepro Tech Inc. (Rocky Hill, NJ) and radioactively labeled using ${ }^{125}$ I-labeled Bolton-Hunter reagent (DuPont-NEN, Wilmington, DE) (13). The labeled proteins were isolated using Sephadex G-25 column (Column PD-10; Pharmacia LKB Biotechnology, Piscataway, NJ) pre-equilibrated with PBS containing $0.1 \%$ gelatin and stored at $-70^{\circ} \mathrm{C}$ after the addition of $1 \%$ bovine serum albumin.

Binding studies with melanoma cell lines were performed by the method of Horuk and colleagues (14). In brief, the cells $\left(1 \times 10^{5}\right.$ cells/ well) in 24-well plates were washed two times with HBSS and incubated with ${ }^{125}$ I-labeled MGSA/GRO $\alpha$ or IL- 8 in the buffer containing $1 \%$ bovine serum albumin at $4^{\circ} \mathrm{C}$ for $3 \mathrm{~h}$. The incubation was terminated by vacuum aspiration of the supernatant. The cells were washed three times in binding buffer, solubilized by the addition of $200 \mu \mathrm{l}$ of $1 \%$ SDS, and transferred to vials for counting. The nonspecific binding was estimated by measuring the binding in the presence of 100 -fold excess of nonlabeled ligand. The binding parameters were calculated using the Lundon II computer program (Lundon Software Inc., Chagrin Falls, OH).

Measurement of MGSA/GRO $\alpha$ and IL-8. MGSA/GRO $\alpha$ in the culture supernatants was measured using an enzyme immunoassay ( $R$ \& D Systems, Minneapolis, MN). IL-8 was measured with a sandwich enzyme immunoassay (15). Plates were coated with monoclonal antihuman IL-8 antibody grown and purified from hybridoma HB9647 which was a gift from Dr. E.J. Leonard (Immunopathology Section, Laboratory of Immunobiology, National Cancer Institute, Frederick, 
MD). Samples were then added and IL- 8 bound to the plates was detected with a two-step incubation with rabbit polyclonal anti-human IL-8 antibody (Upstate Biotechnology Inc., Lake Placid, NY) and swine anti-rabbit immunoglobulins conjugated with horseradish peroxidase (DAKO Corp., Carpinteria, CA). Both immunoassays were specific for their antigen and did not cross-react with other members of the $\alpha$-chemokine family.

Analysis of antileukinate breakdown. Hs 294T and Hep G2 cells, $2 \times 10^{4}$ cells/well, were cultured in 24-well tissue culture plates for $24 \mathrm{~h}$. Then the culture media were replaced with media containing tritiated antileukinate, $0.2 \mu \mathrm{Ci}$, mixed with $100 \mu \mathrm{M}$ unlabeled peptide in each well. The cells were then cultured for the indicated periods. The supernatants were collected and stored at $-70^{\circ} \mathrm{C}$ until use. The breakdown of antileukinate during the cell culture was analyzed on HPLC using an analytical C18 reversed phase column (Waters Co., New Bedford, MA). The peptides were eluted using a gradient from $0.1 \%$ trifluoroacetic acid (TFA) to $80 \%$ acetonitrile in $0.1 \%$ TFA. $1-\mathrm{ml}$ fractions were collected and measured for their radioactivity content using a liquid scintillation counter.

Cell growth assays. The cell lines $\left(2 \times 10^{4}\right.$ cells/well $)$ in $500 \mu \mathrm{l}$ cell culture medium were grown in 24 -well tissue culture plates. After the cells adhered to the plate, the supernatants were aspirated and $500 \mu \mathrm{l}$ of media containing various concentrations of antileukinate were added to the wells. The cells were cultured for period indicated in the text. The culture media were changed to fresh media every $24 \mathrm{~h}$. After incubation, the cells were detached with trypsin-EDTA solution (Life Technologies Inc., Gaithersburg, MD, containing $0.05 \%$ of trypsin and $0.53 \mathrm{mM}$ of EDTA in HBSS without $\mathrm{Ca}^{2+}$ and $\mathrm{Mg}^{2+}$ ) and the cell number was counted using a hemocytometer.

Measurement of cytotoxic activity of the peptide. The cell lines $(4 \times$ $10^{5}$ cells/well) in RPMI-1640 medium containing $10 \%$ fetal bovine serum were incubated with $10 \mu \mathrm{Ci}$ of $\mathrm{Na}_{2}{ }^{51} \mathrm{CrO}_{4}$ (DuPont NEN Co.) for $60 \mathrm{~min}$ at $37^{\circ} \mathrm{C}$ in a $24-w e l l$ tissue culture plate. The cells were washed three times and then incubated in cell culture medium for $30 \mathrm{~min}$ at $37^{\circ} \mathrm{C}$ to allow spontaneous lysis of marginally viable cells. After washing twice, a $200-\mu \mathrm{l}$ aliquot of the antileukinate in cell culture medium was added to each well. The cells were cultured for $16 \mathrm{~h}$ at $37^{\circ} \mathrm{C}$ and then the radioactivity in the supernatants was counted in a gamma radiation spectrometer. Quadruplicate wells received cell culture medium alone or $2 \%$ SDS to determine spontaneous and maximum release, respectively. The percentage lysis was calculated by using the following formula:

$\%$ Lysis $=\frac{(\text { experimental cpm }- \text { spontaneous } \mathrm{cpm})}{(\text { maximum } \mathrm{cpm}-\text { spontaneous } \mathrm{cpm})} \times 100$.

Statistics. The data are expressed as the mean and SD unless otherwise noted. Significance of differences between multiple groups was tested using the analysis of variance and Scheffe's test.

\section{Results}

The effect of antileukinate on the binding of MGSA/GRO $\alpha$ to melanoma cells. The binding of radiolabeled MGSA/GRO $\alpha$ to melanoma cell lines was specific and saturable (Fig. 1). The $K_{\mathrm{d}}$ values calculated were $\sim 6 \times 10^{-9} \mathrm{M}$ and $3 \times 10^{-9} \mathrm{M}$ for Hs 294T and RPMI-7951, respectively. The maximal binding $\left(B_{\max }\right)$ of MGSA/GRO $\alpha$ to the melanoma cell lines was 11 $\mathrm{fmol} / 10^{5}$ cells and $15 \mathrm{fmol} / 10^{5}$ cells, respectively. Thus, the number of MGSA/GRO $\alpha$ binding sites was estimated to be 70,000-100,000/melanoma cell. There was, however, no specific binding of IL-8 to either cell line (Fig. 2).

Antileukinate inhibited the binding of MGSA/GRO $\alpha$ to both of the melanoma cell lines. When the melanoma cell lines, Hs 294T and RPMI-7951, were incubated with ${ }^{125}$ I-labeled MGSA/GRO $\alpha, 1 \mathrm{nM}$, in the presence of antileukinate, the binding was inhibited by antileukinate with an $\mathrm{EC}_{50}$ of $\sim 1 \mu \mathrm{M}$ (Fig. 3).

The production of $\alpha$-chemokines from the melanoma cell lines. The supernatants of melanoma cells cultured for $48 \mathrm{~h}$ were tested for the presence of $\alpha$-chemokines. The concentration of MGSA/GRO $\alpha$ was $24.3 \pm 0.8 \mathrm{ng} / \mathrm{ml}$ in $\mathrm{Hs} 294 \mathrm{~T}$ and $2.6 \pm 0.1 \mathrm{ng} / \mathrm{ml}$ in RPMI-7951 supernatants (Table I). IL-8 was detected at much higher concentrations in the supernatants from both melanoma cell lines (Table I). Liver cancer cell line, Hep G2, also produced detectable amounts of IL-8, however, the concentration was only a small fraction of that seen in the melanoma cell cultures. MGSA/GRO $\alpha$ could not be detected in the supernatants of Hep G2 cells.
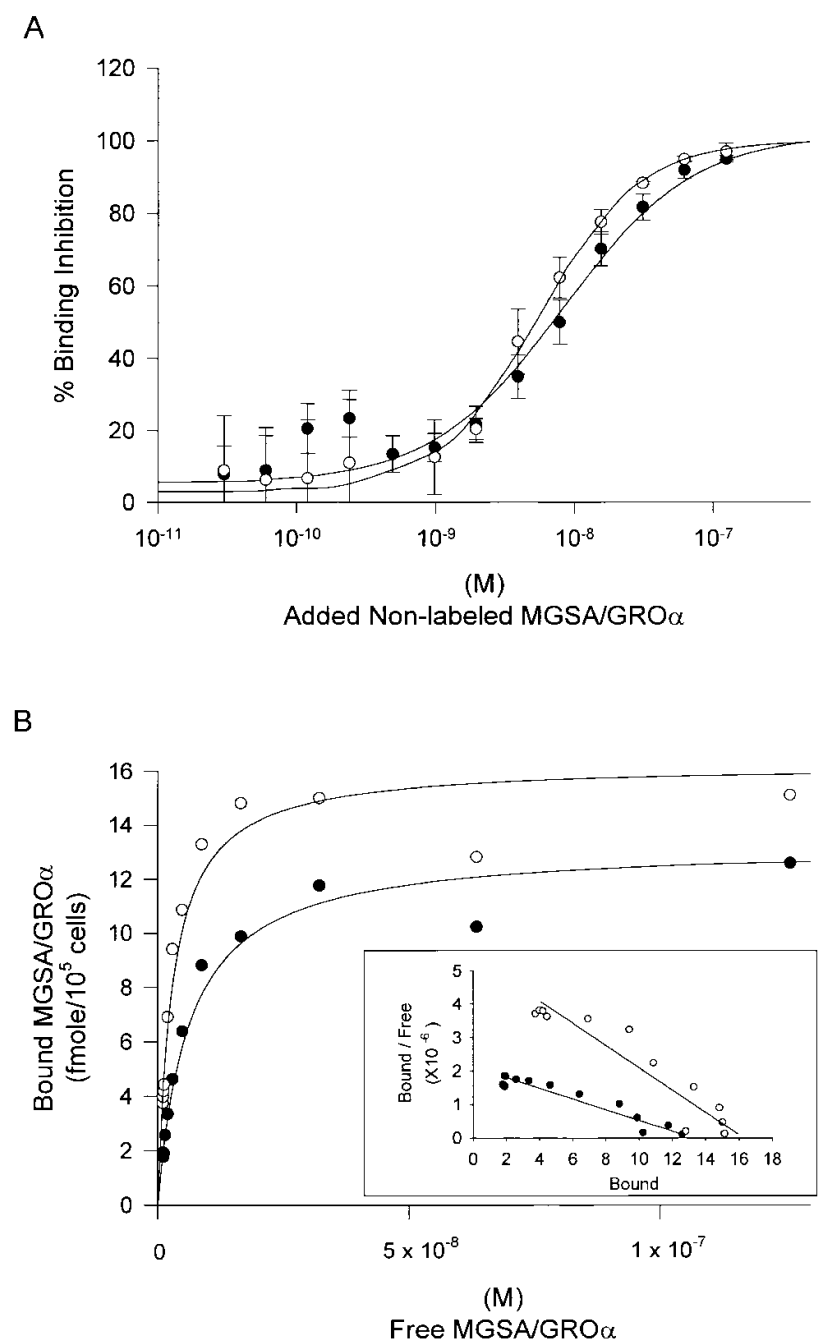

Figure 1. The binding of ${ }^{125}$ I-labeled MGSA/GRO $\alpha$ to melanoma cell lines, Hs 294T and RPMI-7951. The melanoma cells, $1 \times 10^{5}$, were incubated with $1 \mathrm{nM}{ }^{125}$ I-MGSA/GRO $\alpha$ in the presence of various concentrations of unlabeled MGSA/GRO $\alpha$. $(A)$ Binding inhibition curve with Hs 294T (closed circles) and RPMI-7951 (open circles). The lines shown in the graph are the best fit curves calculated using the London II computer program. (B) Binding isotherm transformation. The total amounts of labeled and unlabeled MGSA/GRO $\alpha$ bound to the cells were calculated. Scatchard plots were shown in the inset. 


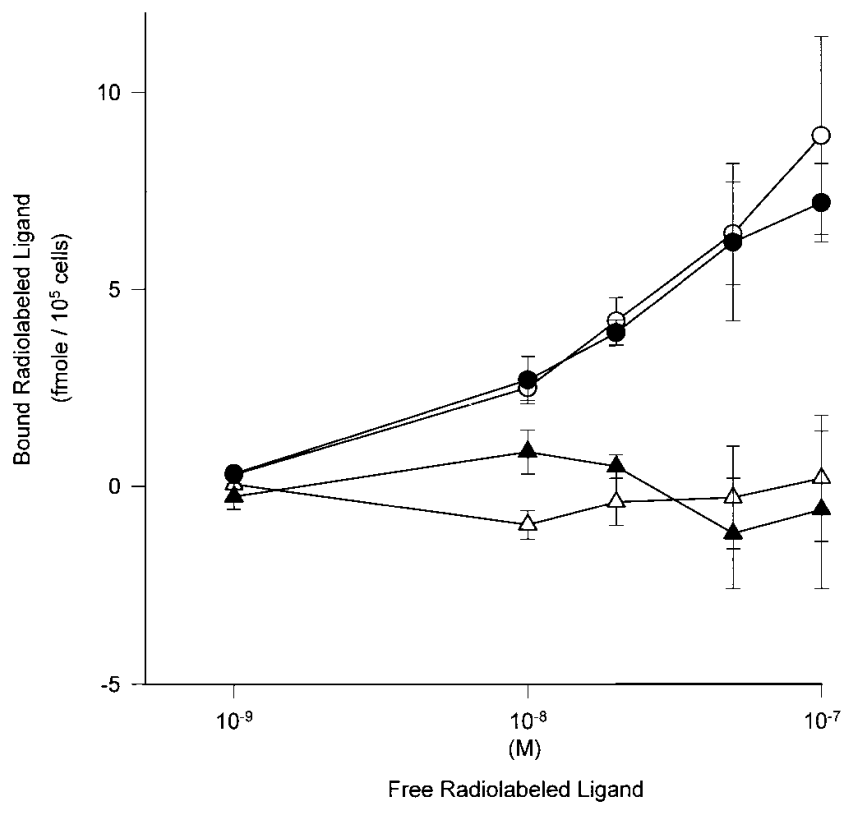

Figure 2. The specificity of the receptor binding. The melanoma cells, Hs 294T (closed symbols) and RPMI-7951 (open symbols), were incubated with indicated concentrations of radiolabeled MGSA/GRO $\alpha$ (circles) or IL-8 (triangles). The nonspecific binding was estimated by the binding in the presence of 100 -fold excess of unlabeled material. Specific binding which is calculated by subtracting non-specific binding from total binding is shown in this figure. IL-8 did not bind specifically to the melanoma cells.

The effect of antileukinate on the growth of melanoma cells. Since antileukinate inhibited the binding of MGSA/GRO $\alpha$ to melanoma cell lines, we tested the ability of antileukinate to suppress autostimulatory growth of melanoma cells. Before these experiments, we examined the time dependent breakdown of antileukinate by Hs 294T melanoma cells and HepG2 liver cancer cells. When the radiolabeled antileukinate in RPMI-1640 medium was analyzed by HPLC, the major peak of the radioactivity was eluted at 50-51 ml (Fig. 4). After a 24-h culture period, the major peak had decreased by $>85 \%$ and there was a transient increase in the peak seen at $41-42 \mathrm{ml}$ (Fig. 4). These findings showed that most antileukinate in both cell cultures disappeared within $24 \mathrm{~h}$ by a two step catabolic process. Therefore, in later experiments we exchanged the culture medium containing antileukinate every $24 \mathrm{~h}$ to maintain the effect of antileukinate.

The growth of melanoma cell lines was inhibited by anti-

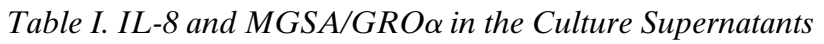

\begin{tabular}{llcc}
\hline & Origin of cell line & IL-8* & MGSA/GRO $\alpha^{*}$ \\
\hline & & $n g / m l$ & $n g / m l$ \\
Hs 294T & Melanoma & $178.3 \pm 1.0$ & $24.3 \pm 0.8$ \\
RPMI-7951 & Melanoma & $138.2 \pm 0.7$ & $2.6 \pm 0.1$ \\
Hep G2 & Liver & $2.0 \pm 0.0$ & $<0.06$ \\
& & & \\
\hline
\end{tabular}

$*$ The cells $\left(5 \times 10^{4}\right)$ were cultured in a 24 -well plate for $48 \mathrm{~h}$. The supernatants were collected and the concentrations of chemokines were measured as described in the text.

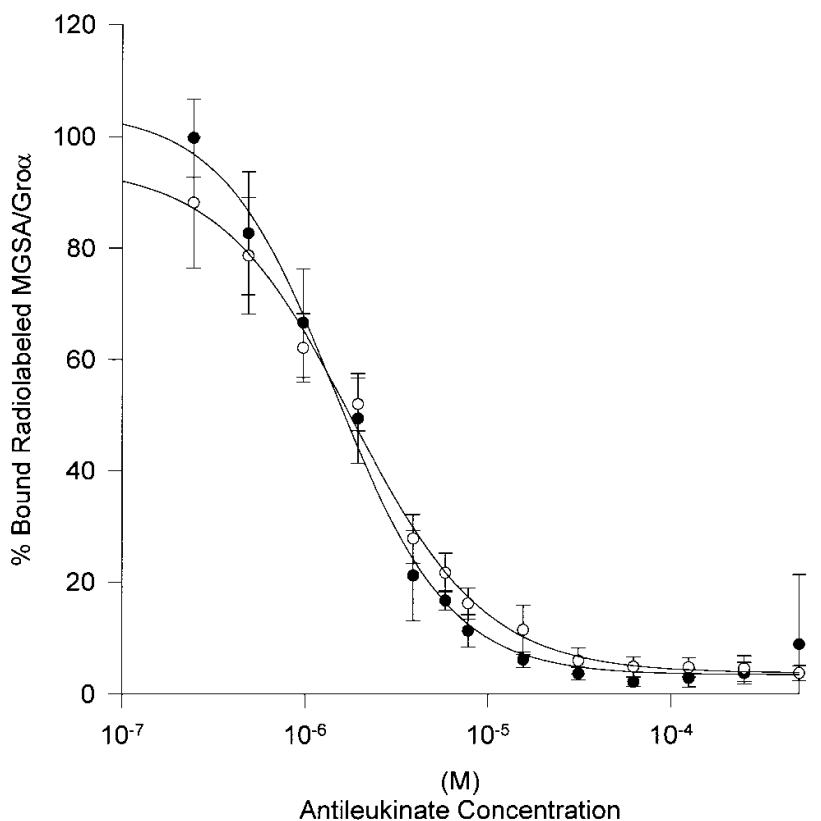

Figure 3. The effect of antileukinate on the binding of radiolabeled MGSA/GRO $\alpha$ to the melanoma cell lines. The melanoma cells, Hs 294T (closed circles) and RPMI-7951 (open circles), were incubated with $1 \mathrm{nM}^{125}$ I-MGSA/GRO $\alpha$ in the presence of different concentrations of antileukinate. The lines shown in the graph are the best fit curves calculated using the London II computer program.

leukinate. We cultured cell lines in the presence of various concentrations of antileukinate for $72 \mathrm{~h}$ and counted the number of cells in the well. The growth of Hs 294T cells was significantly inhibited by $10 \mu \mathrm{M}$ peptide (Fig. $5 \mathrm{~A}$ ) with an $\mathrm{ED}_{50}$ of $18 \mu \mathrm{M}$. Antileukinate also suppressed the growth of RPMI7951 melanoma cells with an $\mathrm{ED}_{50}$ of $31 \mu \mathrm{M}$ (Fig. $5 \mathrm{~B}$ ); however, it did not affect the growth of Hep G2 liver cancer cells (Fig. 5 C).

The inhibition of Hs $294 \mathrm{~T}$ growth was further characterized. It was reversed by the removal of antileukinate from the culture media (Fig. $6 A$ ) and by the addition of $50 \mathrm{nM} \mathrm{MGSA/}$ GRO $\alpha$ to the media (Fig. $6 B$ ). These findings suggest that the

Table II. Cytotoxic Test of Antileukinate on Cultured Cell Lines

\begin{tabular}{lrcr}
\hline & \multicolumn{3}{c}{ Percentage cell lysis* } \\
\cline { 2 - 4 } Peptide added & \multicolumn{1}{c}{ Hs 294T } & RPMI-7951 & Hep G2 \\
\hline \multicolumn{1}{c}{$\mu M$} & & & \\
0 & $0.0 \pm 4.5$ & $0.0 \pm 2.7$ & $0.0 \pm 11.0$ \\
1 & $-4.0 \pm 5.2$ & $-0.8 \pm 2.2$ & $-2.1 \pm 7.5$ \\
5 & $-3.2 \pm 7.2$ & $-2.6 \pm 3.7$ & $-0.8 \pm 8.3$ \\
20 & $-1.6 \pm 3.7$ & $-3.4 \pm 6.3$ & $5.8 \pm 8.3$ \\
100 & $2.4 \pm 7.9$ & $6.8 \pm 11.1$ & $0.9 \pm 2.9$ \\
& & & \\
\hline
\end{tabular}

*The cells labeled with ${ }^{51} \mathrm{Cr}$ were cultured in the presence of various concentrations of antileukinate for $16 \mathrm{~h}$. Then the radioactivity in the supernatants was counted. The percentage cell lysis was calculated based on the amount of chromium released from the cells during the culture. 
A

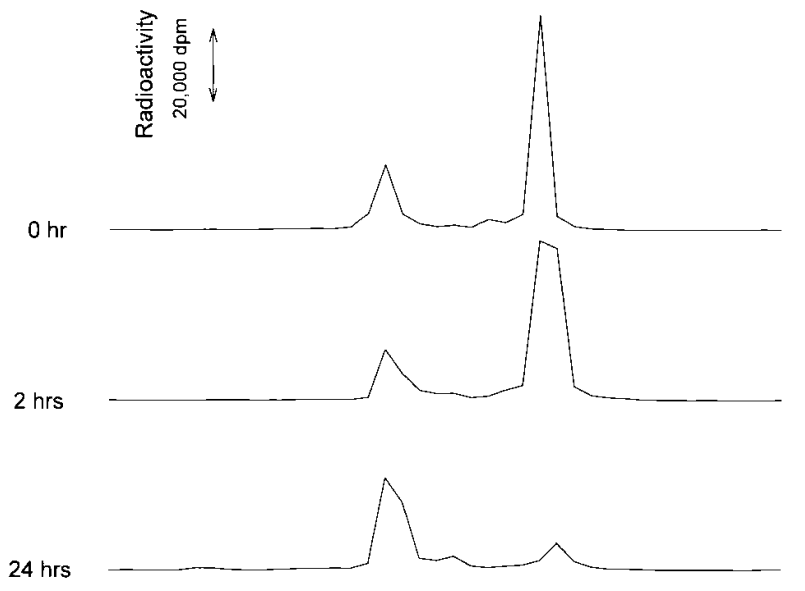

$48 \mathrm{hrs}$
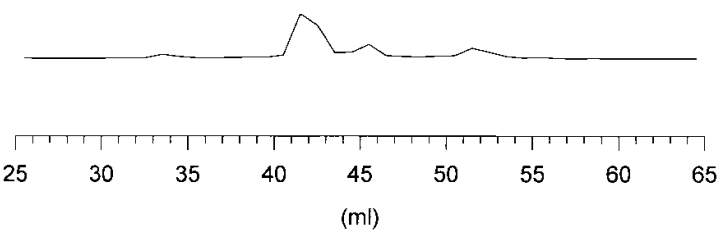

Elution Volume

B

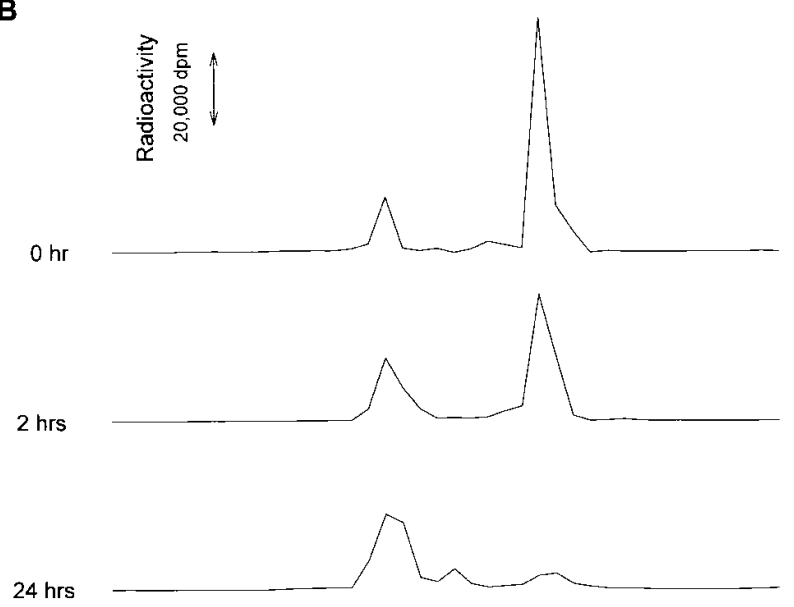

$48 \mathrm{hrs}$

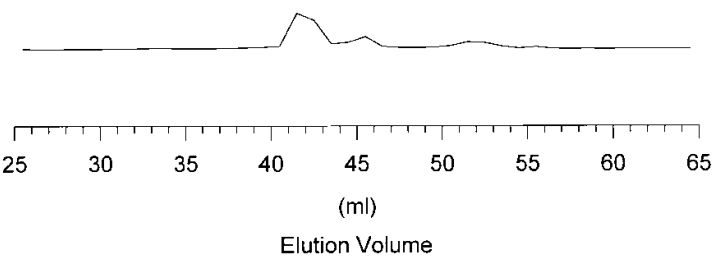

Figure 4. Analysis for the breakdown of antileukinate in the culture of Hs 294T cells and Hep G2 cells. A total concentration of tritium labeled and unlabeled antileukinate of $100 \mu \mathrm{M}$, was added to the culture of Hs $294 \mathrm{~T}$ cells $(A)$ and Hep G2 cells $(B)$. Aliquots of medium were removed at different times and chromatographed on an HPLC Bondapak C18 reversed phase column. The peptides were eluted using a gradient from $0.1 \%$ TFA to $80 \%$ acetonitrile in $0.1 \%$ TFA. 1-ml fractions were collected and measured for their radioactivity using a liquid scintillation counter. The chromatographs show the
Hs $294 \mathrm{~T}$ growth inhibition by antileukinate is associated with the binding inhibition of MGSA/GRO $\alpha$ to the receptors on the Hs 294T cell surface.

Cytotoxicity of antileukinate. To exclude the possible contribution of cytotoxicity of antileukinate to the inhibition of melanoma cell growth, we cultured ${ }^{51} \mathrm{Cr}$-labeled cells in the presence of the peptide for $16 \mathrm{~h}$. Antileukinate did not cause cell lysis of either of the melanoma cell lines or Hep G2 cell line (Table II). Measurements of cell viability by Trypan Blue exclusion also indicated that antileukinate was not toxic to the cells (Fig. 6). The adhesivity of Hs 294T, RPMI-7951 and Hep G2 cells to the culture wells did not alter when antileukinate was added (data not shown).

\section{Discussion}

MGSA/GRO $\alpha$ is a 73 amino acid peptide which shares sequence characteristics of a superfamily of peptides called $\alpha$-chemokines. Richmond and colleagues initially discovered that melanoma cells secreted autostimulatory (autocrine) growth factors $(1-3,16)$. They found that most of the activity was caused by a single acid stable protein of $\sim 16 \mathrm{kD}$ and designated it melanoma growth stimulatory activity (MGSA) (1, 2). MGSA was found to be a mitogen for the melanoma cell line Hs 294T which produces this factor. MGSA was secreted by diverse melanoma cell lines but not by benign nevus cell lines (4), while immunoreactive MGSA was shown in both types of cells (17). cDNA for MGSA isolated from Hs 294T cells was later found to be identical to oncogene growthrelated peptide (GRO $\alpha$ ) gene (18). The formal name for this protein was then designated as MGSA/GRO $\alpha$.

Recently, a second chemokine was found to be important for melanoma cell growth and metastasis in some melanoma cell lines. Schadendorf and colleagues determined that some melanoma cell lines tested secreted IL-8 (19). Both of two IL-8 secreting cell lines studied in more detail were dependent on IL-8 for growth. Antisense oligonucleotides targeted against human IL-8 mRNA inhibited cell proliferation, colony formation in soft agar, and secretion of IL-8 into culture supernatants. In an analysis of 13 different human melanoma cell lines, it was shown that expression of IL-8 correlates with the metastatic potential of melanoma cells in BALB/c nude mice (20).

An interesting experiment further supports the importance of these chemokines in melanoma growth and tumorigenesis. Mintz and Silvers developed a method of producing melanomas by grafting skin from Tyr-SV40E transgenic mice which are highly susceptible to melanoma to Tyr-SV40E hosts of a low susceptibility of the same inbred strain (5). They suggested that growth factors and cytokines known to be produced in wound repair, may trigger the growth and malignant conversion of melanocytes. The association of some human melanomas with an earlier severe blistering sunburn may be an example of a wound-healing process initiating melanoma. This observation is particularly interesting since recent studies indicated that human skin cells express $\alpha$-chemokines after injury. Nanney and colleagues showed that MGSA/GRO $\alpha$ and its re-

elution volume of the radioactivity at different times after addition to the cells. The peptide is substantially eliminated from the cultures within $24 \mathrm{~h}$. 


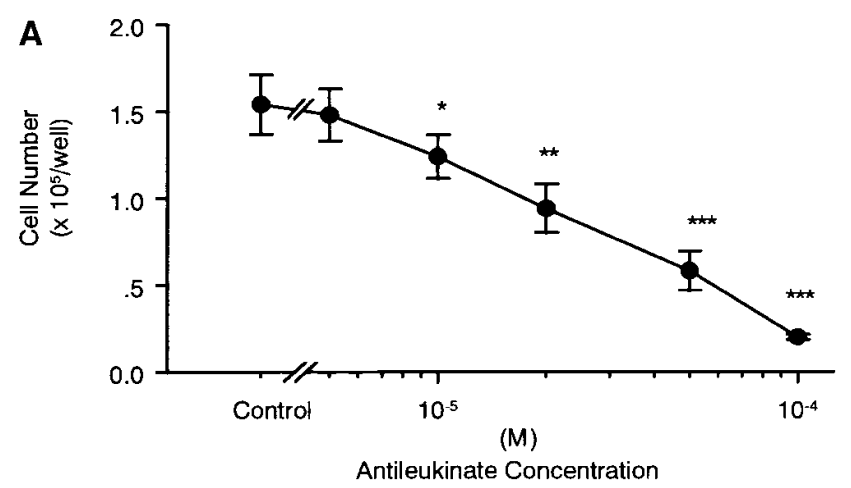

A
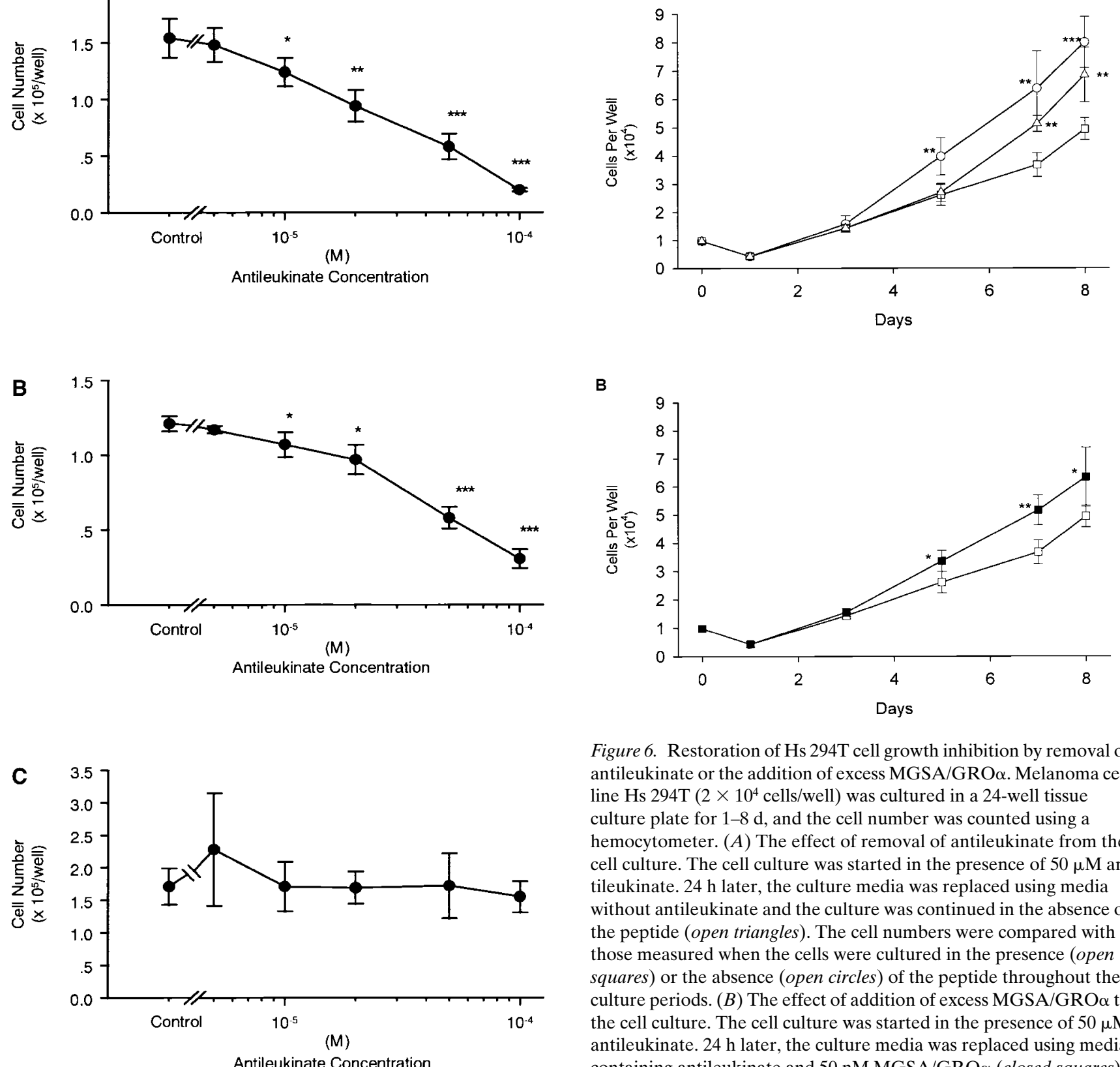

Figure 6. Restoration of Hs 294T cell growth inhibition by removal of antileukinate or the addition of excess MGSA/GRO $\alpha$. Melanoma cell line Hs 294T $\left(2 \times 10^{4}\right.$ cells/well $)$ was cultured in a 24-well tissue culture plate for 1-8 d, and the cell number was counted using a hemocytometer. $(A)$ The effect of removal of antileukinate from the cell culture. The cell culture was started in the presence of $50 \mu \mathrm{M}$ antileukinate. $24 \mathrm{~h}$ later, the culture media was replaced using media without antileukinate and the culture was continued in the absence of the peptide (open triangles). The cell numbers were compared with those measured when the cells were cultured in the presence (open squares) or the absence (open circles) of the peptide throughout the culture periods. $(B)$ The effect of addition of excess MGSA/GRO $\alpha$ to the cell culture. The cell culture was started in the presence of $50 \mu \mathrm{M}$ antileukinate. $24 \mathrm{~h}$ later, the culture media was replaced using media containing antileukinate and $50 \mathrm{nM}$ MGSA/GRO $\alpha$ (closed squares). The cell numbers were compared with those measured when the cells were cultured in the presence of antileukinate alone (open squares). Analysis of variance was used for multiple comparisons of the cell numbers obtained at each culture period. When there was significant difference, the Scheffe's test was performed to establish the significance between two groups. The data significantly different from those with antileukinate $(+)$ were marked: ${ }^{*} P<0.05$; ${ }^{* *} P<0.01$; $* * * P<0.001$ After incubation, the cells were collected and the cell number was counted using a hemocytometer. ( $A$ ) Hs 294T cell line. (B) RPMI7951 cell line. $(C)$ Liver cancer cell line, Hep G2. Analysis of variance was used for multiple comparison. When there was significant difference, the differences between the number of cells without the peptide and those with peptide were tested using the Scheffe's test; ${ }^{*} P<0.05$; $* * P<0.01 ; * * * P<0.001$.

ceptors are present in human burn wounds and may act as a mediator for wound repair (21). MGSA/GRO $\alpha$ and IL-8 was induced by ultraviolet $\mathrm{B}$ radiation in human keratinocyte cell lines (22). 


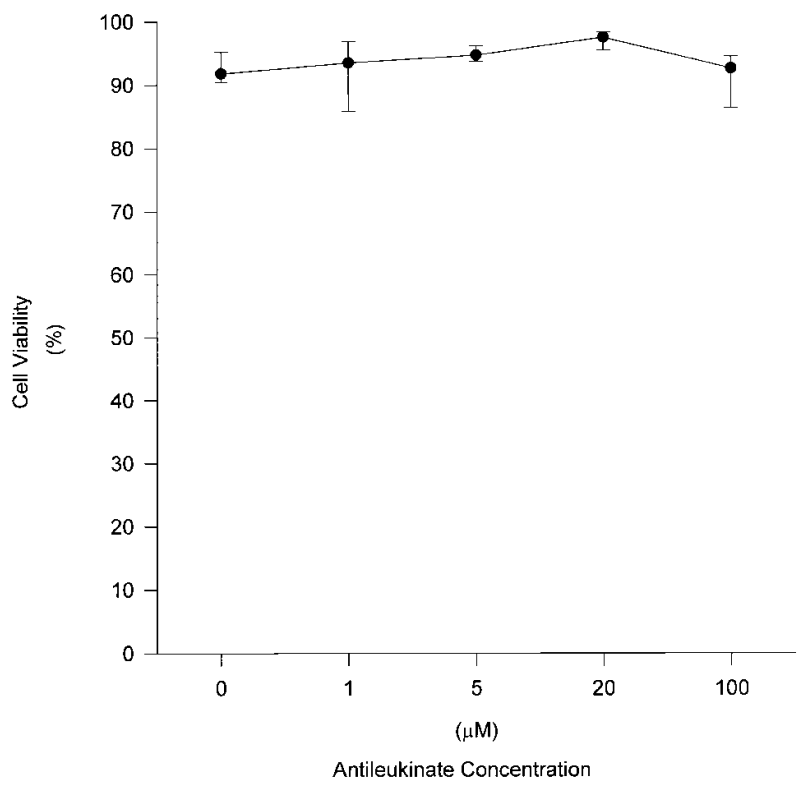

Figure 7. The viability of $\mathrm{Hs} 294 \mathrm{~T}$ cells after the culture for $72 \mathrm{~h}$ in the presence of antileukinate. Melanoma cell line Hs 294T was cultured in the presence of various concentrations of antileukinate for $72 \mathrm{~h}$. The viability of the cells was measured by means of trypan blue dye exclusion. Median $\pm 25 \%$ percentile range of the data are shown.

sion was identified in various melanoma cell lines including Hs 294T. The antibody against IL-8 receptor B partially blocked specific binding of MGSA/GRO $\alpha$. Furthermore, addition of $\mathrm{F}\left(\mathrm{ab}^{\prime}\right)_{2}$ fragments of the anti-IL-8 receptor B or anti-MGSA/ $\mathrm{GRO} \alpha$ monoclonal antibody inhibited serum-independent melanoma cell growth in vitro (11). These studies suggested that, at least a part of, binding of MGSA/GRO $\alpha$ to the melanoma cells is mediated by IL- 8 receptor B on the surface. As shown in Table I, melanoma cell lines produced IL-8 in $\sim 10$ times higher concentration than MGSA/GRO $\alpha$. Therefore, our inability to see IL- 8 binding to melanoma cells may be explained by there being two types of $\alpha$-chemokine receptors on melanoma cells, IL-8 receptor $\mathrm{B}$ and a unique receptor for MGSA/GRO $\alpha$, while IL- 8 receptor B is completely down-regulated by high concentration of IL- 8 . However, the presence of the novel receptor still remains to be examined, since the receptor has not been demonstrated reproducibly. The alternative explanation of our results is that, although IL-8 receptor B rather than a unique $\mathrm{MGSA} / \mathrm{GRO} \alpha$ receptor is expressed on melanoma cells, IL- 8 in the culture made IL- 8 receptor B insensitive to IL-8, but not to MGSA/GRO $\alpha$ through a certain conformational change of the receptor. The latter explanation is possible since we found that the interaction of IL-8 receptor $\mathrm{B}$ with its ligands is not homogeneous (23).

We discovered that a novel hexapeptide, antileukinate, is a potent inhibitor of binding of $\alpha$-chemokines to the receptors on the neutrophils (12). Antileukinate inhibited the binding of radiolabeled IL-8 with an $\mathrm{IC}_{50}$ of $13.7 \mu \mathrm{M}$. The activity of the peptide was specific for $\alpha$-chemokines. Antileukinate also suppressed the binding of radiolabeled macrophage inflammatory peptide-2 $\beta$ (MIP-2 $\beta$ ) to human neutrophils, while it did not affect the binding of radiolabeled MIP- $1 \alpha$, leukotriene $\mathrm{B}_{4}$ or C5a (12). Antileukinate inhibited the enzyme release from neutro- phils stimulated by IL- 8 with an $\mathrm{EC}_{50}$ of $0.8 \mu \mathrm{M}$. The mechanism of antileukinate action is not fully defined. In preliminary experiments, however, the peptide bound to human neutrophils, while it did not interact with IL-8 (data not shown). Together with the finding that some part of IL- 8 binding to human neutrophil was competitively inhibited by antileukinate (12), these findings suggested that antileukinate interacts with $\alpha$-chemokine receptors rather than affects the ligand.

In this study, we tested the effect of antileukinate on autostimulatory growth of melanoma cell lines Hs 294T and RPMI7951. Antileukinate significantly inhibited the binding of MGSA/GRO $\alpha$ to these melanoma cell lines. Since Hs 294T and RPMI-7951 secreted MGSA/GRO $\alpha$ into the supernatant, we examined the effect of antileukinate on the autostimulatory growth of the cells. When the peptide was added to the culture of melanoma cells, it suppressed the cell growth almost completely at $100 \mu \mathrm{M}$. The peptide was more effective on Hs 294T cells than RPMI-7951 cells. The peptide did not affect the growth of the Hep G2 liver cancer cell line, which did not produce MGSA/GRO $\alpha$. The melanoma cell growth inhibition by antileukinate seemed to be associated with specific ability of the peptide to inhibit $\alpha$-chemokine-receptor interaction rather than nonspecific cell growth inhibition by itself or its metabolites. Antileukinate did not affect the growth of SP2/o mouse myeloma cell line stimulated by murine interleukin-6 (data not shown). Antileukinate did not inhibit the growth of Hep G2 cells which metabolized the peptide in a similar way to Hs 294T cells. The cell viability of Hs 294T in the presence of 100 $\mu \mathrm{M}$ peptide was $>92 \%$ as assessed by trypan blue dye exclusion. The peptide did not cause cell lysis of either melanoma cell lines or Hep G2 cells. Furthermore, the removal of the peptide from Hs $294 \mathrm{~T}$ cell culture or the addition of excess MGSA/GRO $\alpha$ to the culture restored the cell growth. These findings suggest that MGSA/GRO $\alpha$ is an essential autostimulatory growth factor for melanoma cells and antileukinate inhibits their growth by preventing MGSA/GRO $\alpha$ from binding to its receptors. These studies raise the possibility that melanoma might be treatable with specific inhibitors of growth factors which control melanoma cell growth.

\section{Acknowledgments}

This work was supported by the Mary and Leon Gibson Foundation grant. E.J. Miller is a Parker B. Francis Fellow in Pulmonary Research.

\section{References}

1. Richmond, A., D.H. Lawson, D.W. Nixon, J.S. Stevens, and R.K Chawla. 1983. Extraction of a melanoma growth-stimulatory activity from culture medium conditioned by the $\mathrm{Hs} 0294$ human melanoma cell line. Cancer Res. 43:2106-2112.

2. Richmond, A., D.H. Lawson, D.W. Nixon, and R.K. Chawla. 1985. Characterization of autostimulatory and transforming growth factors from human melanoma cells. Cancer Res. 45:6390-6394.

3. Richmond, A., and H.G. Thomas. 1986. Purification of melanoma growth stimulatory activity. J. Cell. Physiol. 129:375-384.

4. Lawson, D.H., H.G. Thomas, R.G. Roy, D.S. Gordon, R.K. Chawla, D.W. Nixon, and A. Richmond. 1987. Preparation of a monoclonal antibody to a melanoma growth-stimulatory activity released into serum-free culture medium by Hs0294 malignant melanoma cells. J. Cell. Biochem. 34:169-185.

5. Mintz, B., and W.K. Silvers. 1993. Transgenic mouse model of malignant skin melanoma. Proc. Natl. Acad. Sci. USA. 90:8817-8821.

6. Oppenheim, J.J., C.O. Zachariae, N. Mukaida, and K. Matsushima. 1991. Properties of the novel proinflammatory supergene "intercrine" cytokine family. Annu. Rev. Immunol. 9:617-648.

7. Murphy, P.M., and H.L. Tiffany. 1991. Cloning of complementary DNA encoding a functional human interleukin-8 receptor. Science (Wash. DC). 253: 
1280-1283.

8. Holmes, W.E., J. Lee, W.J. Kuang, G.C. Rice, and W.I. Wood. 1991. Structure and functional expression of a human interleukin-8 receptor. Science (Wash. DC). 253:1278-1280.

9. Mueller, S.G., W.P. Schraw, and A. Richmond. 1994. Melanoma growth stimulatory activity enhances the phosphorylation of the class II interleukin-8 receptor in non-hematopoietic cells. J. Biol. Chem. 269:1973-1980.

10. Moser, B., L. Barella, S. Mattei, C. Schumacher, F. Boulay, M.P. Colombo, and M. Baggiolini. 1993. Expression of transcripts for two interleukin 8 receptors in human phagocytes, lymphocytes and melanoma cells. Biochem. J. 294:285-292.

11. Norgauer, J., B. Metzner, and I. Schraufstatter. 1996. Expression and growth-promoting function of the IL-8 receptor beta in human melanoma cells. J. Immunol. 156:1132-1137.

12. Hayashi, S., A. Kurdowska, E.J. Miller, M.E. Albright, B.E. Girten, and A.B. Cohen. Synthetic hexa- and heptapeptides which inhibit IL-8 from binding to and activating human blood neutrophils. J. Immunol. 154:814-824.

13. Bolton, A.E., and W.M. Hunter. 1973. The labeling of proteins to high specific radioactivities by conjugation to a 125 -I-containing acylating agent: application to the radioimmunoassay. Biochem. J. 133:529-539.

14. Horuk, R., D.G. Yansura, D. Reilly, S. Spencer, J. Bourell, W. Henzel, G. Rice, and E. Unemori. 1993. Purification, receptor binding analysis, and biological characterization of human melanoma growth stimulating activity (MGSA). J. Biol. Chem. 268:541-546.

15. Ko, Y.-C., N. Mukaida, A. Panyutich, N.N. Voitenok, K. Matsushima, T. Kawai, and T. Kasahara. 1992. A sensitive enzyme-linked immunosorbent assay for human interleukin-8. J. Immunol. Methods. 149:227-235.
16. Richmond, A., D.H. Lawson, and D.W. Nixon. 1982. Release of an autostimulatory growth activity by human malignant melanoma cells. Cold Spring Harbor Conference. Cell Proliferation. 9:885-897.

17. Richmond, A., R. Fine, D. Murray, D.H. Lawson, and J.H. Priest. 1986. Growth factor and cytogenetic abnormalities in cultured nevi and malignant melanomas. J. Invest. Dermatol. 86:295-302.

18. Richmond, A., E. Balentien, H.G. Thomas, G. Flaggs, D.E. Barton, J. Spiess, R. Borkoni, U. Francke, and R. Derynck. 1988. Molecular characterization and chromosomal mapping of melanoma growth stimulatory activity, a growth factor structurally related to beta-thromboglobulin. EMBO J. 7:20252033.

19. Schadendorf, D., A. Moller, B. Algermissen, M. Worm, M. Sticherling, and B.M. Czarnetzki. 1993. IL-8 produced by human malignant melanoma cells in vitro is an essential autocrine growth factor. J. Immunol. 151:2667-2675.

20. Singh, R.K., M. Gutman, R. Radinsky, C.D. Bucana, and I.J. Fidler. 1994. Expression of interleukin 8 correlates with metastatic potential of human melanoma cells in nude mice. Cancer Res. 54:3242-3247.

21. Nanney, L.B., S.G. Mueller, R. Bueno, S.C. Peiper, and A. Richmond 1995. Distributions of melanoma growth stimulatory activity of growth-regulated gene and the interleukin- 8 receptor $\mathrm{B}$ in human wound repair. Am. J. Pathol. 147:1248-1260.

22. Venner, T.J., D.N. Sauder, C. Feliciani, and R.C. Mckenzie. 1995. Interleukin- 8 and melanoma growth-stimulating activity are induced by ultraviolet B radiation in human keratinocyte cell lines. Exp. Dermatol. 4:138-145.

23. Hayashi, S., M. Stevens, E. Miller, A. Kurdowska, R. Strieter, A. Walz, and A. Cohen. 1995. Characterization of the binding of epithelial neutrophil activating peptide-78 (ENA78) to interleukin-8 receptors. FASEB J. 9:A247. 